\title{
EL NEUROPUNK Y LA CIENCIA FICCIÓN HISPANOAMERICANA
}

\author{
POR \\ Nelson Darío GONZÁLEZ \\ University of Toronto
}

Nos proponemos ilustrar que el neuropunk es una de las orientaciones más notorias en la ciencia ficción de Hispanoamérica del siglo XXI. ${ }^{1}$ Es una literatura que evidencia la evolución reciente en campos como la neuromedicina y los computadores a la vez que es antecedida por un legado literario y especulativo de heterogénea divulgación. Como neuropunk se debe entender aquella literatura en la que el órgano del cerebro oficia de foco neurálgico del relato, ya sea como tema, personaje, clave de lectura o incluso lugar. Se trata a su vez de una literatura adscrita al género del biopunk, es decir una literatura que mezcla los asuntos propios del cyberpunk-o mejor del postcyberpunk, ya se verácon temáticas derivadas de la biotecnología tales como la clonación, la genética, la inteligencia artificial o la biología sintética. Que quede claro que el neuropunk no es una inclinación restringida al ámbito de Hispanoamérica; es una tendencia narrativa a nivel internacional, integrada por ejemplo en la obra "biopunk" de autores anglosajones de cierto reconocimiento, como la estadounidense Octavia Butler(1947-2006) y el británico Paul McAuley (1955). ${ }^{2}$ Está asociado a la creciente mitologización en torno al cerebro que Roland Barthes detalla ya a mediados del siglo XX en el ensayo "El cerebro de Einstein", en donde se muestra cómo los sesos del genio alemán se posicionan como la metáfora por excelencia de la inteligencia humana.

En breve, los textos en cuestión son especulaciones literarias filtradas por la convicción de que el entendimiento del cerebro es crucial para establecer la naturaleza de la vida humana, siendo este órgano el componente corporal regulador de un modo aún abstruso de nuestras experiencias sensoriales y mentales. "Tengo cerebro, luego existo" es sentencia de partida de esta literatura, para a renglón seguido, deslizar la insinuación de que "como tengo el cerebro existo". En estas ficciones, el cerebro -y con ello el ser

1 Este artículo se desprende de nuestra tesis doctoral De mentes, entes y dementes: Un repaso históricocrítico de la ciencia ficción hispanoamericana. Desde sus orígenes hasta nuestro días (1870-2013) (2014), donde se hace una contextualización detallada de esta producción literaria.

2 Por ejemplo la trilogía Xenogenesis (1987-2000) de Butler y White Devils (2004) de McAuley, admiten también un análisis como el llevado en este ensayo. 
humano- es retratado como una materia moldeada y moldeable por fuerzas a las que se halla sujeto. Al mismo tiempo, en esta literatura se vislumbran transformaciones reales y vigentes en materia social, económica, biológica, política, sexual y psicológica. Se alude a empresas multinacionales y de biotecnología, regímenes y ciudadanos corruptos, intervenciones médicas increíbles (pero acaso pronto posibles), comercio, distribución y consumo de drogas, fronteras visibles e invisibles, en fin, a temas de actualidad. Sin embargo, con el creciente auge de la biotecnología, esta literatura concibe cada vez más inminente el momento de la singularidad, es decir, ese instante en que nuestra especie deje de ser lo que es y pase a mudar en otra cosa - una estirpe "poshumana". En ese horizonte venidero, el cerebro es considerado como el eslabón decisivo en la cadena evolutiva. En el futuro divisado por las narrativas neuropunk, todo puede faltar excepto cierta materia gris.

Si bien estas ficciones están puntuadas por un alto grado de novedad científica, en verdad hacen parte de una tradición literaria, filosófica y especulativa de larga data. En todo caso, son sintomáticas del marco epistemológico actual donde es creciente la prevalencia de nociones neuromédicas. En este sentido, ilustran más de siglo y medio de adelantos científicos en los estudio del cerebro y en las reflexiones en torno al enigma de la consciencia humana. ${ }^{3}$ No obstante, es una literatura que hereda ante todo los saberes derivados de la llamada "década del cerebro". ${ }^{4}$ De manera que renueva el llamado que hace cincuenta años expresó el escritor inglés J.G. Ballard (1930-2009) al señalar que la ciencia ficción debería dejar de girar en torno a los viajes por el espacio exterior y en cambio concentrarse en las ciencias biológicas y la exploración del interior de los seres humanos. ${ }^{5}$

Ahora bien, la tradición literaria en Hispanoamérica exhibe una serie de variopintas narraciones que especulan sobre las naturaleza humana. En efecto, en la obra de algunos autores decimonónicos puede ya rastrearse un afán por tantear definiciones al respecto y reservar en ese arreglo el cerebro para alguna elevada función. Sin embargo, lo que singulariza a muchas de las obras escritas en los pasados veinticinco años es ser capaces de enunciar una articulación menos vaga del funcionamiento de ese órgano. Así, "Horacio

\footnotetext{
Según el neurobiólogo Owen Flanagan la filosofía de la mente se consolida hacia las últimas décadas del siglo XIX y las primeras del XX, pero no cobra reconocimiento profesional después de 1950.

4 Con este nombre, en 1990 George H. W. Bush, el presidente de los Estados Unidos, lanza un ambicioso programa para sensibilizar a los ciudadanos estadounidenses sobre los beneficios derivados del estudio del cerebro. A partir de este momento, apunta Malcolm Jeeves, el público en general será cada vez más consciente de la intrincada relación entre nuestra mente y nuestro cerebro, y de que esta relación podrá ser mejor monitoreada a medida de que las técnicas neuromédicas son perfeccionadas (179).

5 Ballard es de los primeros en anunciar este cambio. Así, en 1962, escribe que "los grandes desarrollos del futuro inmediato tomarán lugar, no en la luna o marte, sino en la Tierra, y es el espacio interior, no el exterior, el que ha de explorarse. El único planeta extraño de verdad es la Tierra" (117 cursiva del original, nuestra traducción).
} 
Kalibang o los autómatas"(1879) del argentino Eduardo Holmberg (1852-1937) apunta el siguiente interrogante "¿qué es el cerebro, sino una máquina, cuyos exquisitos resortes se mueven en virtud de impulsos mil y mil veces transformados? ¿Qué es el alma, sino el conjunto de esas funciones mecánicas?" (32; énfasis mío). Aún cuando la mención de resortes y funciones mecánicas puede pasar hoy de rudimentaria, el relato se entretiene con la eventualidad de crear seres artificiales que sean indistinguibles de los humanos y las consecuencias de aquel hecho. Al respecto, críticos como Elvio Gandolfo y Pablo Solomonoff destacan cómo el clima de paranoia que proyecta el cuento anticipa el tipo de ficciones como las del escritor estadounidense Philip K. Dick (1928-1982), que van a ejercer profundo ascendiente en muchos de los autores hispanoamericanos de ciencia ficción de finales del siglo XX y comienzos del XXI. Solomonoff apunta que "la discusión se plantea entre lo 'posible' y lo 'concebible' [...] entre la filosofía trascendentalista acorde a una espiritualidad romántica y el materialismo de corte positivista que arraigó mejor en la estética modernista, los cuales terminan por mezclarse"(17-18). De hecho, la brecha entre lo 'posible' y lo 'concebible' continuará siendo motivo de debate a lo largo del siglo XX en tanto que esa escisión parece estrecharse, al punto que el neuropunk proyecta hasta qué punto en el imaginario popular del siglo XXI el cerebro es concebido como atajo para superar tal separación.

Por otra parte, Querens (1890) de Pedro Castera (1845-1906), acaso la primera novela mexicana de ciencia ficción (Fernández Delgado 51), es para Luis Mario Schneider " $[\ldots]$ la primera novela latinoamericana en la que el hipnotismo, la energía esotérica, dan motivo y fundamento a la creación artística" (25). Así, con base en las enseñanzas sobre el hipnotismo desarrolladas por el neurólogo francés Jean-Martin Charcot (1825-1893), pionero de la neurología moderna, esta novela refiere la capacidad de inducir el sueño en otra persona a través de la voluntad. " ¡Cuántas horas de mi vida desaparecían absorbidas en el estudio de su cerebro [...]!”(139-40) reseña en la novela el científico con el poder mental de hacer dormir a una mujer. La teoría de transferencia del pensamiento y de sensaciones por medio de procedimientos propios de la teoría del "magnetismo animal" enunciada por el médico Franz Mesmer (1734-1815) es la base epistemológica de la narración. ${ }^{6}$ Esta obra y otras del período están punteadas por el implícito asentimiento de la existencia del "alma", como ilustran desde su mismo título Póstumo el transmigrado: El hombre que resucitó en el cuerpo de su enemigo (1872) y Póstumo el envirginado: Historia de un hombre que se coló en el cuerpo de una mujer (1882) del escritor puertorriqueño Alejandro Tapia y Rivera (1826-82). Asimismo, otro ejemplo para destacar es El donador de almas (1899) del mexicano

6 De acuerdo al "magnetismo animal" o "mesmerismo", existe una invisible fuerza que los animales ejercen y que puede llegar a tener efectos físicos. Para Charcot, con base en esto, la hipnosis es un estado anormal del funcionamiento nervioso, exclusivo de ciertas mujeres histéricas. Sigmund Freud (18561939) se contó entre sus estudiantes. 
Amado Nervo (1870-1919), que narra que a un doctor, uno de sus colegas le regala un alma para que le sirva de compañía. Y aunque la novela está infiltrada por nociones derivada de la doctrina espiritista expuesta por partidarios de ella como el pedagogo francés Allan Kardec (1804-1869) en el célebre El libro de los espíritus (1857), hace explícita la ubicación del alma en el órgano del cerebro. De esta manera es puntualizado cuando, por circunstancias imprevistas, el alma obsequiada debe pasar a compartir el cuerpo del doctor que la recibió como regalo: “[...] con una sutileza del todo espiritual, encarnó en el hemisferio izquierdo del cerebro del doctor, dejando confinado el espíritu de éste en el hemisferio derecho" (66). ${ }^{7}$ Con esto, el depositario halla que "merced a un caso único desde que el mundo es mundo, tenía dos almas" (66). La correspondencia entre cerebro y alma es manifiesta: “¡En su cerebro había algo de inverosímil! Había dos entendimientos y dos voluntades al propio tiempo (69 cursiva del original)". Por lo demás, como en la novela de Castera, la voluntad se establece como el atributo por excelencia del alma, postura que coincide con el pensamiento del filósofo alemán Arthur Schopenhauer(1788-1860), quien sostiene en El mundo como voluntady representación (1819; vol 2 1844) que más real que la misma realidad es la voluntad de vivir. Por ello, toda manifestación del mundo natural tiene como explicación base esta entelequia, cuyo planteamiento filosófico se granjeará amplio crédito en Hispanoamérica. ${ }^{8}$ La novela de Nervo expone además el embrollado modo de pensar con que despunta el inicio del siglo XX, cuando conceptos de las ciencias naturales característicos de disciplinas como la astronomía y la física convergen junto a otros de índole paranormal, según son postulados por disciplinas controversiales como el espiritismo y la parapsicología.

A lo largo del siglo XX, junto a los avances en la neurología, disciplina inaugurada en buena medida por las investigaciones del médico español Santiago Ramón y Cajal (1852-1934), dos invenciones tecnológicas pasan a ejercer una influencia profunda y suministran materia para especulaciones narrativas sobre la condición humana: hablamos del cinematógrafo y la televisión, durante la primera y la segunda mitad de siglo, respectivamente. Asimismo, el afán por circunscribir una identidad cultural define la singularidad de la producción hispanoamericana. Es empero una aspiración

7 La precisión sobre el hecho de que cada hemisferio del cerebro tiene "vida propia", independiente uno del otro, se empieza a develar en la década de 1960, cuando se practican las primeras operaciones quirúrgicas para separar los hemisferios cerebrales (comisurotomía) en pacientes que presentaban un cuadro clínico con síntomas de epilepsia.

8 Según este planteamiento, el universo está integrado por una fuerza sin motivo que llamamos voluntad. Ahora bien, la primera traducción al español de la totalidad de los textos de Schopenhauer se publica en España en 1928; fue antecedida por una traducción parcial aparecida entre 1896 y 1902, cuando a la sazón Nervo escribía El donador. Por tanto, es probable que Nervo tuviera conocimiento de estas ideas a través de la obra de Friedrich Nietzsche (1844-1900), quien estudió en detalle la de Schopenhauer y partió de ella para formular algunos de sus propios planteamientos filosóficos. 
irresoluta que está sentenciada a prolongarse. ${ }^{9}$ En consecuencia, es corriente que obras de ciencia ficción hispanoamericana exploren contradicciones propias del dualismo cartesiano e insinúen que este presupuesto filosófico está viciado al fundarse sobre una dicotomía que falla en revelar cómo la esfera de lo físico afecta lo incorpóreo y cae irremediablemente en un abismo hermenéutico. Por tanto, a despecho de su aparente rigor inicial, el dualismo cuerpo-espíritu se ve confrontado con la irremediable necesidad de introducir un factor mágico o una división adicional al interior de su quintaesencia -un "demonio" lo denomina J.D. Bernal-. Esta contradicción termina por arrollar con cualquier pretensión de coherencia metafísica y científica. ${ }^{10}$

Esta discordancia es asimilada y expuesta por la ciencia ficción hispanoamericana a través de ficciones donde la identidad humana es confrontada en estruendosas situaciones donde lo científico y lo tecnológico saltan a un primer plano en tanto que cuerpo y alma son dos entidades con los que fabula esta literatura. Por ende, muchos de estos relatos no salvan las contradicciones en uno de los aspectos que paradójicamente más se esmeran por precisar: el metafísico. ${ }^{11}$ Esto es rastreable en varias de las narraciones que componen Las fuerzas extrañas (1906) del argentino Leopoldo Lugones (1874-1938), donde es adoptada una iconografía de corte darwinista junto a otras de tenor fantasioso aunque revestidas de apariencia técnica. "Un fenómeno inexplicable", por ejemplo, narra las circunstancias que constriñen a un hombre al sufrir el rompimiento de la unidad que lo constituía. Tras educarse en la India en las artes que confieren poderes a los yoghi, este individuo resuelve observar a su doble en medio de un desdoblamiento, "ver qué era lo que salía de mí, siendo yo mismo, durante el sueño extático"12 (132; énfasis en el original). A partir de aquella experiencia referida, la sombra de un mono persigue al personaje, sin quitarle la mirada de encima: "desde entonces no se aparta de mí. Lo veo constantemente. Soy su presa. A donde quiera él va, voy conmigo, con él. Está siempre

9 Darko Suvin destaca que en el corazón de la ciencia ficción late la pesquisa por la identidad humana, en términos culturales y planetarios. Así, según Suvin, la ciencia ficción no se pregunta por el Ser Humano y el Mundo sino por cual tipo de ser humano y cual mundo, y porque ese ser en ese mundo (7).

10 Bernal habría delineado en The World, the Flesh, and Devil: An Enquiry into the Future of the Three Enemies of the Rational Soul (1929) la línea argumental para el desarrollo de la futura ciencia ficción (Slusser 96). Para él, la humanidad se aproxima a una instancia en la que alcanzará un nuevo estado de existencia por medio de la transformación de su entorno y su propio ser. Pero para llegar a ese punto, deberá vencer antes tres obstáculos: el mundo, la carne y el demonio, es decir, el ámbito material, su cuerpo y una forma innata de división o dualidad dentro de la propia mente, intocable por alteración mecánica o psicológica (Slusser 98-9).

11 En Intermitente recurrencia Luis Cano sostiene que ese interés por lo metafísico es una característica de la ciencia ficción hispanoamericana y que, en ello, se asemeja a la tradición de la ciencia ficción producida en Inglaterra.

12 El cuento también llama a los desdoblamientos "traslaciones conscientes", siguiendo el léxico teosófico. Estas son proyecciones voluntarias del "cuerpo astral” fuera del cuerpo físico. 
ahí. Me mira constantemente, pero no se le acerca jamás, no se mueve jamás, no me muevo jamás" (132; énfasis en el original).

Por otra parte, Eugenia (1919) del médico mexicano (de origen cubano) Eduardo Urzaiz (1876-1955) recrea los principios defendidos por la eugenesia, como lo es la manipulación sexual en pos de una supuesta mejora de rasgos hereditarios. Entretanto, "La psiquina" (1917) del escritor argentino Ricardo Rojas (1882-1957) ahonda en las potencialidades de algunas drogas químicas para alterar la experiencia sensorial. La psiquina es un alcaloide preparado para provocar la separación del cuerpo y el espíritu de quien lo consume. Es usado con breve éxito para resucitar a un recién fallecido. Estas dos ficciones se caracterizan por su extravagancia, como también el peculiar relato "La doble y única mujer" (1927) del ecuatoriano Pablo Palacio (1906-1947), que trata de una mujer bicéfala. Con todo, para antes de 1950, son acaso dos obras inspiradas en el cinematógrafo las que exhiban acaso un mayor perfil de extrañeza, XYZ: Novela grotesca (1934) del peruano Clemente Palma (1872-1946) y la afamada La invención de Morel (1940) de Adolfo Bioy Casares (1914-1999). Las palabras con que Nicholas Daly define la recepción del proyector cinematográfico en Inglaterra coinciden en abordar la representación que estas dos novelas proyectan, Daly sostiene que el aparato cinematográfico fue percibido por el público como una entidad transformadora del cuerpo humano. Más que el ferrocarril, el cine se presentó como una tecnología mágica, incluso misteriosa (7). De forma afín, el cinematógrafo se concibe en la novela de Palma capaz de producir réplicas vivientes de actores hollywoodenses a partir de un proceso técnico con albúmina de huevo que desarrolla el ingeniero Rolland Poe, también conocido como el doctor XYZ. La invención, por su parte, corresponde a la reseña de un fugitivo con sus experiencias en una isla abandonada cuando es confrontado por un mecanismo que proyecta una vez tras otra, día tras día, las imágenes de lo que hiciera allí durante dos semanas un grupo de antiguos residentes, entre quienes se destaca Morel, el propio inventor de la máquina, construida con la aspiración de crear la eternidad, en otras palabras, la vida eterna.

A mediados del siglo XX, la literatura de ciencia ficción, tal como la concebimos hoy, comienza a ser escrita y publicada en Hispanoamérica. La aparición de una producción hispanoamericana circunscrita dentro de los parámetros literarios y mercadotécnicos popularizados por los pulps norteamericanos se remonta justo a este período, que está marcado por una generalizada paranoia. En consecuencia, la tecnología es retratada como un medio de intervención, explotación y manipulación del cerebro. Así lo deja entrever el desenlace de "Inocente Maquiavelo Reforzado" (1955) del argentino Héctor Germán Oesterheld (1919-1977), uno de los relatos publicados en la célebre revista argentina Más Allá (1953-57) que mayor revuelo causó entre los lectores por su excentricidad. El desenlace del cuento es una escena en la que el protagonista entra a "[...] uno de esos electrobares donde el mozo le pone a uno un casco con electrodos que inducen al 
cerebro de uno toda clase de pensamientos estimulantes" (77). Así, es proyectado un futuro en donde el pensamiento es manipulado a voluntad. Del mismo modo, algún tipo de manipulación cerebral es involucrado en Los altísimos (1959) del chileno Hugo Correa (1926-2008) y en la célebre historieta El eternauta (1957-9) de Oesterheld. En estas dos narraciones son descritos seres con capacidades inmensamente superiores que subyugan a la humanidad, en ocasiones a través de alucinaciones inducidas. Por lo demás, la década de 1950 es un período en que las drogas neurolépticas son introducidas en el mercado y desplazan prácticas quirúrgicas contingentes como la lobotomía, las cuales son desestimadas con rapidez. ${ }^{13} \mathrm{Al}$ mismo tiempo, en la mayoría de los países hispanoamericanos la televisión pública es inaugurada. Con el paso de los años, su influjo se hará mayor. Los televisores serán vistos como la puerta a otros tiempos u otras dimensiones e involucrados en aplicaciones fantasiosas donde el entorno y cuerpo humanos son materia de cambio. ${ }^{14}$

Por otra parte, cuando un comité de la escuela de medicina de Harvard establece en 1968 que el criterio para dictaminar la muerte de un individuo ha de basarse en el funcionamiento de su cerebro, esto conlleva cambios cognoscitivos de gran envergadura en la práctica médica. Malcolm Nicolson destaca que la adopción del criterio de la muerte cerebral se debe en buena medida al desarrollo exitoso en las cirugías de trasplantes de órganos y a la creación posterior de una demanda por órganos frescos para trasplantar (29-30). Pasa a ser éticamente aceptable remover órganos de pacientes con muerte cerebral para trasplantarlos a otros individuos. Un problema moral se trasforma así en uno técnico (Schlich 89). Simultáneamente, las neurociencias comienzan a establecerse como áreas autónomas de investigación (Vidal 40).

Bioy Casares escribe Dormir al Sol (1973), novela en la que un doctor de un "Instituto Frenopático" practica pruebas quirúrgicas con el propósito de trocar las almas entre humanos y perros. En efecto, el alma del narrador concluye confinada en el cuerpo de un canino, después de que el doctor explica que "Descartes pensaba que el alma estaba en una glándula del cerebro [... pero] no se equivocó en lo principal. El alma está en

${ }^{13}$ Con la invención de los neurolépticos, prácticas como la lobotomía son acusadas de destruir la consciencia. Con todo, cuando el primer neuroléptico es comercializado -bajo el nombre de Cloropromazina o Thorazine-, con frecuencia se lo califica de "lobotomía química".

14 Dos relatos que acentúan la importancia de este aparato son "La grieta" (1978) de la mexicana Manú Dornbierer, donde la televisión permite la comunicación entre mundos paralelos, y "El futuro es tiempo perdido" (1991) del también mexicano Guillermo Lavín, donde la televisión presenta "en directo" el pasado. También valga destacar al respecto Los titeres (1969) de Correa y Proceso a Faubritten (1976) de la mexicana Marcela del Río (1932) por mostrar aplicaciones basadas en el aparato de televisión. Asimismo, juega un papel central en la obra del mexicano Pepe Rojo (1968), tanto en sus cuentos cyberpunk más logrados, "Ruido gris" (1996) y "Conversaciones con Yoni Rei" (1998), como en su única novela, Punto cero (2000). 
el cerebro y podemos aislarla" (150). La terminología empleada y la temática referida en esta novela componen a la vez un signo de actualidad y anacronismo. En otras palabras, la manipulación médica del cerebro es contrapuesta a observaciones sobre el alma y a rudimentos de la filosofía cartesiana. Su heterogeneidad epistemológica es representativa de la ciencia ficción hispanoamericana, su adscripción casi exclusiva del dualismo cuerpo-espíritu y de lo que Marshall Bergman denomina el "modernismo del subdesarrollo", en tanto que la su raigambre técnica de este y otros textos que tratamos puede calificarse de "estridentes", "burdas" y "rudimentarias". ${ }^{15}$ Esto lo patentiza "Los inmortales" (1967), un cuento que Bioy Casares escribe junto a Jorge Luis Borges (18991986) bajo el seudónimo de Bustos Domecq, que es acaso el único cuento de la obra borgesiana (aunque quizá sea más adecuado referirse aquí a la obra bioyborgesiana) que se acerca a esbozar directamente una teoría "fisicalista" de la mente humana. ${ }^{16}$ Detalla la manera en que un grupo de personas acceden a la inmortalidad a través los procedimientos que un médico explica al narrador: "Reemplazados los componentes del organismo, corruptibles de suyo, por otras tantas piezas inoxidables, no hay razón alguna para que el alma, para que usted mismo, Bustos Domecq, no resulte Inmortal" (367). Con base en esta base epistemológica, el médico resuelve amputar todos los miembros de los clientes, reemplazando todos los órganos por partes mecánicas, excepto el cerebro que es alojado en una caja de metal. ${ }^{17}$ Así, el narrador describe la escena: "[...] cuatro personajes o muebles. Su color era el mismo de las paredes; el material, madera; la forma, cúbica. Sobre cada cubo, un cubito, con una rejilla y debajo, su hendija de buzón. Bien escrutada la rejilla, usted notaba con alarma que desde el interior lo seguían unos a modo de ojos" (367). El relato es una adaptación de la "paradoja de Putnam", que es popularizada años después por la película The Matrix (1999) e implícitamente convenida por los escritores de corte neuropunk. Según esta especulación filosófica, está loco todo hombre que descubre que es sólo un cerebro en una bañera y su realidad una ilusión

15 Berman sostiene que "el modernismo del subdesarrollo es forzado a construir fantasías sobre los sueños de la modernidad, a alimentarse de una intimidad y una lucha con milagros y fantasmas. En aras de ser fiel a la vida de la que brota, es forzado a ser estridente, burdo y rudimentario" (232; énfasis mío).

16 La mente humana entendida como la interrelación de componentes físicos, básicamente, como una máquina cuyo funcionamiento puede descifrarse en su totalidad.

17 Carlos Abraham destaca dos posibles antecedentes literarios para este relato, Last and First Men (1930) de Olaf Stapledon y "The Jameson Satellite” (1931) de Neil R. Jones: “[...] ambos textos describen cerebros orgánicos albergados en estructuras metálicas (también en forma de caja) que se ocupan de sus funciones orgánicas y garantizan su inmortalidad" (81). Asimismo, Abraham señala que es muy numerosa la cantidad de textos que abordan este tópico. Entre otros, están los libros: That Hideous Strength (1945) de Clive S. Lewis, Star Trail to Glory (1941) de Edmond Hamilton, donde "uno de los personajes principales es un cerebro conservado dentro de una cápsula con miembros para posibilitar su movilidad" (81). Esta novella fue publicada en 1947 en Buenos Aires con el título Hacia la gloria por la ruta de los astros en la revista Hombres del futuro. 
creada por un computador, aún si tiene razón. Como vive fuera de la realidad, aunque sea en realidad un cerebro en una bañera, cuando él lo dice, lo que afirma es falso. ${ }^{18}$

"Los inmortales" como los relatos venideros del neuropunk del siglo XXI perfilan el fenómeno cultural que Fernando Vidal denomina como la "“cerebralización' de la persona/personalidad/identidad humana" ("the 'cerebralization' of personhood"), ${ }^{19}$ cuando el cerebro pasa a abrigar todas las propiedades del individuo. "Este cuento puede entenderse como una parodia de esta 'cerebralización' de la naturaleza humana”. Vidal destaca que, "[...] contrario a una de las principales preocupaciones en la sociedad industrial, los cerebros nunca envejecen en el mundo imaginario. De hecho, los cerebros han incorporado las cualidades del alma, no sólo como lugar de esta, pero ante todo como substancia inmaterial por excelencia" (52; énfasis mío). En el relato, el doctor le dice al aterrorizado Domecq, "quién nos iba a decir que el homo sapiens, el antropoide apenas desbastado de Darwin, lograría tal perfección” (367). Estas palabras evidencian la "darwinistis" que Raymond Tallis reprocha a mucho del pensamiento moderno, es decir, la aplicación indiscriminada de la teoría de la evolución para analizar todo aspecto y comportamiento humano. Asimismo, Tallis denuncia que el fervor en las nacientes neurociencias lleva a un exagerado uso de sus alcances, al punto que todo comportamiento pasa a ser explicado en términos neuronales. Tallis a esto lo denomina "neuromania" y lo llama una reducción epistemológica. ${ }^{20}$ Ahora bien, este fenómeno, que apenas asoma en "Los inmortales", es el sustrato cultural que impulsa y circunscribe la producción venidera de neuropunk.

Un hecho para resaltar es la invención en 1977 de la técnica de "Imágenes por Resonancia Magnética Funcional" (IRMf). Este procedimiento clínico ejercerá gran influencia en el desarrollo de las investigaciones científicas del cerebro porque permite como nunca antes una visualización en tiempo real de su funcionamiento. Al mostrar variaciones en la demanda de oxígeno en partes del cerebro a medida que este opera, esta técnica permite 'ver' los efectos en la distribución sanguínea cerebral cuando son efectuadas ciertas tareas mentales, bajo el efecto de ciertos medicamentos o al sufrir de algún trastorno, etc. De cierta manera, es como si el cerebro fuera perforado por la mirada, como si fuera visto por televisión. Al mismo tiempo, bajo el ascendiente de las ciencias de la cognición (cognitive sciences) y de diferentes ramas de la neurociencia, diversas

\footnotetext{
${ }^{18}$ La "paradoja de Putnam" es punto de partida para el concepto que el filósofo David Chalmers propone a finales de siglo XX, llamado 'cerebro en una cubeta' (33), el cual refiere la posibilidad de entender el cerebro como un órgano sin miembros en un contenedor. Esta noción será muy influyente en el estudio sobre el funcionamiento del cerebro y en el subgénero literario que se dará a conocer como cyberpunk. Es referida en Tan cerca de la vida (2010) de Santiago Roncagliolo.

${ }_{19}$ Personhood es una palabra sin equivalente exacto en español. Es traducida como identidad, personalidad o persona, pero ninguna de estas opciones abarca su significado por completo.

${ }^{20}$ La fascinación, que Tallis denomina "neuromania", considera que la actividad cerebral no es simplemente necesaria sino suficiente para la manifestación de una consciencia humana.
} 
líneas de estudio se ocupan de determinar la(s) manera(s) en que el cerebro posibilita la mente. ${ }^{21}$ Por consiguiente, fenómenos mentales como la memoria y la creatividad son interpretados desde una óptica fisicalista. En este marco, el relato "Primera línea" (1983) del argentino Carlos Gardini (1948) advierte sobre ciertos empleos del tratamiento con substancias químicas del cerebro. Este texto además representa el despuntar de un lento cambio paradigmático en la valoración de las letras hispanoamericanas de ciencia ficción. Al ser premiado en un concurso literario que incluía a Borges entre los miembros del jurado, el ámbito de la literatura canónica y el de la ciencia ficción se cruzan en este relato. ${ }^{22}$ El relato trata sobre los MUTIL (Móvil Unitario Táctico Integral para Lisiados), un grupo de soldados mutilados en una guerra "convencional" quienes, mediante intervenciones quirúrgicas, son convertidos en máquinas para matar; se hace hincapié en el deshumanizador condicionamiento psicológico a través de una imagen repetida en cuatro ocasiones: una inyección en el cerebro. Por ejemplo, “[...] el soldado Cáceres oía el ruido en el cielo y recordaba ese cielo de ruidos, y cómo le habían sacado la inyección del cerebro" (36). En efecto, estos soldados son una especie de doloridos cyborgs: "Tenemos este cuerpo, decía, gracias a la metralla del enemigo" (37; énfasis en el original). Al final, cuando concluye la guerra, se sugiere que van a ser desaparecidos para borrar cualquier indicio sobra esa operación militar. En breve, este relato propone una sátira sobre las fuerzas armadas argentinas y su intervención en la llamada guerra de las Malvinas; para Luis Pestarini, “[...] es un ejercicio que desnuda el militarismo como un absurdo" (436).

Hacia finales del siglo XX, el interés por estudiar el cerebro se extiende con rapidez. El gran acicate de un número masivo de investigaciones científicas derivadas de "la década del cerebro". ${ }^{23}$ Así, lo que fue la exploración espacial en los años sesenta lo constituye la investigación del cerebro en los noventa. Algunos científicos concluyen que la cantidad de conocimientos neurológicos obtenidos en esta década es tan vasta que supera en mucho todo lo estudiado en los cincuenta años previos (Tandon 205). Por otra parte, para finales de siglo, tras la introducción del programa informático World Wide Web en 1991, el Internet comienza a popularizarse a escala global. En estos años comienza el llamado cyberpunk mexicano y es escrita Cárcel de árboles (1992) del guatemalteco Rodrigo Rey Rosa (1958). En este relato, un grupo de prisioneros es objeto de crueles experimentos con el beneplácito del gobierno. Sus lenguas son extirpadas y sus cerebros intervenidos para atrofiar su memoria y hacer desaparecer en ellos cualquier rasgo de individualidad. Cano opina que en esta novela lo realmente

${ }^{21}$ De acuerdo Hans Adler y Sabien Gross, esta búsqueda constituye el principal interés de las nuevas disciplinas adscritas a la neuromedicina.

22 "Primera línea" gana el Premio Nacional de Cuento en 1982, con un tribunal que también incluía a José Donoso.

${ }^{23}$ Ver nota 4. 
significativo, para su inclusión dentro de la ciencia ficción, “[...] es la adopción de un principio que aspira a establecer cierto tipo de verdad, y que entreteje referencias a procedimientos e investigadores que trabajan en el área de la neurocirugía" ("Cárcel" 396) ${ }^{24}$ Cárcel inicia con un epígrafe extraído de la obra de Ludwig Wittgenstein, donde se afirma que el pensamiento es una capacidad que opera con signos y que, por lo tanto, no debe ser considerada como una actividad mental. Cano destaca que esta referencia es relevante en la caracterización de la ciencia ficción en Hispanoamérica: “¿Es la filosofía una ciencia? ¿Es suficiente una reflexión sobre la filosofía del lenguaje para clasificar el cuento [novella] como representativo del discurso de una de las ramas de la ciencia?" "Cárcel” 395).

Por otra parte, el cyberpunk escrito por autores mexicanos tiene una faceta política, a diferencia del escrito por autores anglosajones. En estos relatos donde se mezclan la cibernética y las tecnologías de la información, las corporaciones y multinacionales económicas son percibidas como fuentes generadoras de disolución del tejido social y de la identidad nacional a través de prácticas económicas deshumanizadoras. José Luis Ramírez, quien hace parte de este conjunto de escritores, declara que el interés de esta literatura se cifra en el momento actual de su país, acorde con la función figurativa que Ursula K. Le Guin le concede al futuro en la ciencia ficción. En otras palabras, todos estos textos son metáfora del presente. ${ }^{25}$ La obra del mexicano Pepe Rojo (1968) es ilustradora de ello. El relato "Ruido gris" es protagonizado por un reportero que, con implantes de cámaras transmisoras en sus córneas, deambula por una ciudad en pos de asaltos, suicidios y demás actos violentos que puedan ser emitidos en el canal de televisión que financió en parte su cirugía. "Conversaciones con Yoni Rei"-contenido en Yonke-tiene el formato de un guión para un "infocomercial" televisivo; su protagonista es Yoni Rei, "[...] un bebé de laboratorio, propiedad de TELCOR INTERNACIONAL" (69). Su biografía es desplegada: "Yoni Rei fue criado por una máquina siempre sonriente, fue amamantado por un pezón de silicón, con calor simulado, para que no extrañara. Yoni Rei fue comprado como carne para experimentar" (71). El propósito de esta publicidad

${ }^{24}$ En efecto, Cárcel está colmada de referencias a la neurología, al punto que en buena medida es su razón de ser el configurar una reflexión ética sobre los alcances de esa disciplina médica. Cano, tras un análisis detallado, establece que "La mayoría de los nombres de los personajes que entran en contacto con los prófugos y sus escritos provienen de individuos reales cuya investigación se ha concentrado predominantemente en la rama de la neurología, con énfasis en los procedimientos y mecanismos de producción del lenguaje" (“Cárcel” 394).

25 Le Guin hace esta puntualización en 1976, en la introducción a la segunda edición de The Left Hand of Darkness (1969). Ramírez admite que "[...] nosotros abordamos el presente del México de los noventa -crisis económica, globalización, revolución, violencia urbana, narcotráfico, internet, apertura comercial, la estúpida creencia de que habíamos dejado el tercer mundo y estábamos a punto de pertenecer al primero- y ese presente, es el mismo que los escritores etiquetados cyberpunk en los Estados Unidos, vivieron diez años antes. A falta de una etiqueta mejor, también en México se denominó a la nueva corriente: cyberpunk". 
es al parecer asentar cierta idea comercial en la mente del público: "Ellos también son humanos, muestra tu humanidad aceptándolos" (80; énfasis en el original). En todo caso, la actitud de Yoni no se presta a engaños, aunque es subversiva y dócil a la vez:

$\begin{array}{ll}\text { Corte A: } & \text { Cuarta conversación con Yoni Rei, } \\ \text { ENTREVISTADOR: } & \text { ¿Qué es lo que Yoni Rei le pediría al mundo? } \\ \text { YONI: } & \text { Lo que más quiero yo es que un brazo mecánico me acaricie } \\ & \text { en las noches, antes de dormir. } \\ \text { ENTREVISTADOR: } & \text { Si hay algo que le quisiera decir al mundo, ¿qué sería? } \\ \text { YONI: } & \text { Que chinguen a su madre, ya que por lo menos tiene una. }\end{array}$

En el siglo XXI, el post-cyberpunk, el biopunk y el neuropunk convergen en obras que muestra un mayor grado de envolvimiento que el cyberpunk en la problemática de la consciencia humana. Sin embargo, en estos textos la concepción del ser humano sufre también una simplificación, en correspondencia con las condiciones que la tecnología biónica ejerce sobre las experiencias humanas. La consciencia es reducida a un plano único en que las experiencias son estimadas a través de una tercera persona que substituye la primera. Para William Haney, “[... ] la tecnología biónica podría limitar las experiencias fenomenológicas al desalentar el acceso a la pura consciencia" (103). En este marco, la figura del zombi va a cobrar nueva relevancia en la ciencia ficción hispanoamericana del siglo XXI, como signo de cierta "in-consciencia" ${ }^{26}$ Signo de la desazón experimentada al ser incapaz de oír la voz interior por causa de la interferencia que produce la tecnología internalizada

A primer plano es llevada la extravagancia de un mundo en donde los individuos se han vuelto máquinas y estas a su vez se han visto cobrar vida, como en Gel azul (2007) y El estruendo del silencio (2009) del mexicano Bernardo Fernández (1973), conocido también como Bef. Estos dos textos hilvanan fantasías en futuros disímiles, el uno es próximo, el otro remoto. Pero convergen en un revelador personaje contextual: HumaCorp. Así, en $\mathrm{Gel}$, esta corporación japonesa es la productora del "[...] tanque cilíndrico de plexiglás, lleno de gel proteínico” (13) que “[...] es la ilusión de todo cibernauta. En el momento en que usted se interfasa se olvida del resto del mundo. El nirvana, heaven on earth, un orgasmo eterno" (64). ${ }^{27}$ Gracias a estos tanques, sus usuarios nunca necesitan desconectarse de la Red. Pero la situación se embrolla cuando un grupo de traficantes de órganos se aprovecha de estos cibernautas, que inmersos en el mundo virtual no se dan cuenta que desaparecen partes de su cuerpo. En El estruendo, Koji C. Kobayashi, dueño de HumaCorp, es quien está detrás de la construcción de la nave interestelar rumbo a Épsilon Eridani, marco en que se encuadra esta ficción. La nave es comandada

\footnotetext{
26 Vale mencionar aquí la novela Malas hierbas (2010) de Pedro Cabiya, que asocia un trastorno mental a la mitología del zombi.

${ }^{27}$ La tecnología (cibernética) como sucedáneo de la ideología religiosa es una noción que infiltra Gel.
} 
por el señor Ká, un insectoide tecnoorgánico, es decir, un robot con “exosesqueleto de quitina" (135). ${ }^{28}$ La singularidad de la narración consiste en que, a través de extraños sueños, despierta una consciencia en esta inteligencia artificial. Acaso la explicación para este singular evento resida en las palabras escritas por Norman Weiner leídas en los archivos por el capitán de la nave: "Los sistemas digitales pueden desarrollar neurosis" (229 cursiva del original). Como sea, el lector no puede sino cuestionarse que ese insectoide prefigure el último vestigio de la cultura humana. "Errare Posthumanum Est." (287) es la conclusión cerca del final.

Así, un aura de indeterminismo distingue a la ciencia ficción con el cambio de milenio, en consonancia con el sentimiento preponderante de incertidumbre tras la caída en descrédito de las grandes metanarrativas descrita por teóricos como JeanFrançois Lyotard y Fredric Jameson. Así que la perplejidad es una condición ligada a la consolidación del neuropunk, como lo ilustra "Pesadilla en el hipotálamo" (1999) del colombiano Julio César Londoño (1953). Este relato patentiza además cuán propio de esta literatura es la ostentación de cierta gnosis acerca del funcionamiento cerebral. El cuento relata los esfuerzos emprendidos por el narrador para deshacerse del gusano que carcome su cerebro y con ello su facultades nemotécnicas: "[...] ya desesperado, me tomé un vermicida para caballos. [...] Calculé que podía matarlo con un par de tomas, sólo que no estaba muy seguro de sobrevivirlo. Por lo pronto el animal se asiló astutamente en el hipotálamo, central cibernética del cerebro. Como quien dice: 'Nos vamos a hacer pasito, ¿verdad?"' (énfasis mío). Este argumento lleno de humor sirve de vía para modular reflexiones sobre la facultad de la memoria: “[...] tuve la sensación de tener ruñida la memoria y así era, literalmente hablando. El olvido es un fenómeno de carácter continuo, no discreto [...]" (énfasis en el original). En ello, el cerebro se muestra como personaje y territorio por ser demarcados:

¿Cómo recordamos voluntariamente? [...] ignoramos es que este pique es un reto para nuestro cerebro, quien lanza un haz de avisados bibliotecarios hacia la memoria a frenéticas velocidades, como un ejército riguroso que revisara una ciudad casa por casa en busca de un personaje. El cerebro parece entonces una ciudad negra rasgada aquí y allá por súbitos diamantes. (énfasis mío)

El cerebro es distinguido como una ciudad obscura y como el ejército que la protege. Es lugar y personaje. Su contradictoria duplicidad revela la irresolución que elude al dualismo cuerpo-espíritu en su configuración. Por otra parte, cuando el protagonista logra

${ }_{28}$ Este relato es excepcional al interior de la producción hispanoamericana en lo referente a que puede categorizarse dentro del tipo de ficción conocido en inglés como generation starship. En El estruendo, así se describen las circunstancias que capitanea el señor Ká: "Una nave espacial basada en la estructura de las medusas lanzada hacia la estrella más próxima con dos seres humanos en suspensión animada y toda la cultura humana grabada en su banco de memoria" (201; énfasis en el original). 
sacar al insecto de su cabeza descubre que sus capacidades mentales son mayores con el gusano morando en su mollera. Resuelve por ello devolverlo a su interior: "[...] lo puse con cuidado en el pabellón de la oreja derecha -no fuera a caerse y sufrir un traumatismo cerebral-". A la postre, la narración concluye en una atmósfera de indeterminación que prevé no obstante la inminencia de cierta transformación en la psiquis humana: "Y si bien mi ruñido cerebro es menor cada día, el suyo crece y sus razonamientos son muy buenos porque no están entorpecidos por prejuicios de ninguna clase ni por el necio narciso de la especie humana. Quizá es él quien me dicta estas líneas”. El final del relato oscila entre un cándido optimismo y una indolente desolación, síntoma de nuestros tiempos.

Otro excelente ejemplo del neuropunk lo constituye "Incidente Johnson-Muñoz" (2008) del cubano Gabriel J. Gil Pérez (1987), un relato contenido en la antología En sus marcas, listos... ifuturo! Cuentos cubanos de ciencia ficción deportiva que refiere el "neuro feed-back", una suerte de pugilismo mental que constituye el deporte del siglo XXII. La narración relata una contienda entre "[...] el actual campeón del orbe, el estadounidense Michael 'Mind-Boggler' Johnson, y su retador, el cubano Manuel 'SinCráneo' Muñoz, quien un año antes cayera en Baltimore ante el yanqui en el combate final por el título Mundial Profesional". Los dos contendientes se enfrentan "[...] mente contra mente, según el principio de neurofeed-back por mediación tecnológica" (énfasis en el original) y portan "neurocascos amortiguadores de los golpes mentálicos". De forma que "Con fiero instinto, ambos boxeadores, maestros del neuro feed-back, buscaban las zonas cerebrales más sensibles y menos protegidas de su contrario, amagaban y arremetían, como en cualquier otro deporte de lucha".

Al igual que la narración de Londoño, "Incidente" exterioriza cierto conocimiento del funcionamiento biológico del cerebro. Leemos que “[...] el norteamericano optó por cambiar prudentemente de táctica hacia una pelea de desgaste: mientras amagaba con directos a la pituitaria, comenzó de manera subrepticia a hacer estallar neuropéptidos en el cerebro del antillano, que poco a poco fueron adormeciéndolo" (énfasis mío). Los neuropéptidos son diminutas moléculas usadas por las neuronas para comunicarse entre ellas. A la postre, la integración entre las dos mentes combatientes alcanza tal grado que se convierten en una sola: "Fue entonces cuando 'Mind-Boggler', curioso, decidió a su vez escudriñar en el cerebro de 'Sin-cráneo' las mismas zonas. Y así fue como se vio de repente invadido por una intensa emoción. Un orgullo que no le pertenecía; la satisfacción de descubridor del cubano, por haber finalmente hallado el por tantos años buscado secreto de la telepatía". ${ }^{29}$ Ambos adversarios mueren y el combate es declarado nulo.

${ }^{29}$ Ahora bien, la relación del neuropunk con la literatura que aborda la telepatía y otras experiencias extrasensoriales es enmarañada. Es indiscutible que el cerebro es fundamental en mucha de esta literatura. Al mismo tiempo, es innegable que la base científica de estos planteamientos es vaga y ha sido objetada. Muchos de sus supuestos datan de finales del siglo XIX, formulados por miembros de 
Al final, “[...] aquella unión ¿telepática? que los convirtió por breves pero intensísimos segundos en una sola mente también habría alterado sus cerebros de tal modo que, al ser luego separados, tales órganos simplemente no pudieran ya encargarse de coordinar las funciones más elementales de sus propios cuerpos". Con todo, el relato concluye con que un par de técnicos electrónicos habaneros podrían ser los responsables y “[...] la causa de todo fue sólo un par de 'mejoritas' improvisadas que se les ocurrió hacerle por su cuenta al $M I O$ [intensificador de ondas mentálicas] a última hora, para compensar lo inestable que se pone a veces el voltaje en la capital cubana y ¿por qué no? probar a mejorar sus funciones...". En este relato como en mucha de esta tecnología, la tecnología del futuro muestra aún un perfil vacilante.

Textos como La cabeza del puertorriqueño Pedro Cabiya (1971), Ygdrasil (2005) del chileno Jorge Baradit (1969) y Tan cerca de la vida (2010) del peruano Santiago Roncagliolo (1975) escenifican mundos inmersos en poderosas dinámicas sociales asociadas a prácticas biomédicas y biotecnológicas en las que el funcionamiento del cerebro es la implícita piedra angular. Son novelas de una profunda hibridez que refieren procesos homogeneizadores del capitalismo y la globalización, y conciben el cuerpo como una máquina moldeable y de recambio. La cabeza, por ejemplo, describe cómo la cabeza de una mujer es conectada a una serie de máquinas, antes de ser trasladada a otro cuerpo. Ygdrasil refiere una construcción tecnológica que desvía las almas y las encarna en un procesador de última generación. Macarena Areco la llama una novela "cyber-splatter-punk" (845) debido a "[...] su insistencia en el cuerpo y en el dolor, las torturas y fragmentaciones a que son sometidos los personajes y su estética cercana al gore, la vinculan al splatterpunk" ${ }^{30}$ (847; énfasis en el original). En Tan cerca, se detalla la forma y la problemática asociada con el hecho que una corporación comercializa cadáveres de suicidas en pos de alcanzar su propósito de crear vida artificial. Con todo, a pesar de que los escenarios recreados en estos textos se antojan novedosísimos, están infiltrados por deseos atávicos y ambiciones que se remontan a la especulación de los alquimistas del medioevo.

Society for Psychical Research, como Frederic W. H. Myers, quien acuña el término de "telepatía" en 1882. Con todo, la transmisión del pensamiento como postula la telepatía es materia de especulación de variadas obras. Así, para enumerar sólo algunos, mencionamos cinco textos de autores cubanos que involucran esta temática: "Amoroso planeta" (1983) y Fábulas de una abuela extraterrestre (1998) de Daína Chaviano (1960); Cecilia después o ¿por qué la Tierra? (1987) de F. Mond (1949); y ¿A dónde van los cefalomos? (1964) y Síder (1994) de Ángel Arango (1926-2013) -la tercera novela de la saga de los cefalomos-.

30 El splatterpunk es un término acuñado por David Schow en 1986 y es un tipo de literatura que "[...] incluye agresividad explícita, torturas, violaciones" (Areco 847). Areco señala que "[m]ientras la negación del ciberpunk ha sido leída como indicadora del carácter masculino del género, la inmersión del splatterpunk en lo abjecto sería una respuesta feminista de recuperación del cuerpo" (847 cursiva del original). 
Asimismo, la clonación es una temática repetida; la adscriben novelas como Cuando llegaron los dioses (2001) del hondureño Orlando Enríquez (1923-2012) y El sueño de Mariana (2008) del salvadoreño Jorge Galán (1973). En esta última narración la clonación es una práctica comercial en una ciudad dividida en dos mundos, que origina reflexiones sobre la globalización: "[...] al lamentar la muerte de su amiga, la señora Lena, le ofrece fabricarle una idéntica. Pero no tendría alma, objeta Mariana. Eso no importaba a los habitantes de los 'megaedificios', donde se desconocían los sentimientos o se huía de ellos" (45). Por otra parte, varios de los relatos de las antologías compiladas por el costarricense Iván Molina Jiménez (1961) hacen referencia al cambio climático y adscriben principios de la 'biopolítica'.

La influencia de la obra de Borges es prevalente en muchas de otras obras, como La segunda enciclopedia de Tlön (2007) del chileno Sergio Meier (1965), considerada la primera de corte steampunk en Hispanoamérica. ${ }^{31}$ El clon de Borges (2010) del colombiano Campo Ricardo Burgos López (1968) es una obra que involucra dos características que permean conspicuamente la actual producción hispanoamericana: la temática de la clonación y la fascinación por las enfermedades mentales. Miguel Ospino, el protagonista, sufre de una patología psíquica, cifrada en una desmedida obsesión en Borges $^{32}$. Mantiene prisionero al clon de Borges para gozar con las obras que escribe este sosías del autor argentino.

En fin, el neuropunk como el biopunk patentizan el hecho de que "[...] la biotecnología abandonó el ámbito científico para incorporarse a las reglas del capitalismo" (Cohen, "El nacimiento" 36). Marcelo Cohen trae a colación las observaciones de Critical Art Ensemble, un autor colectivo que arguye que la hiperracionalización al interior del capitalismo de libre mercado configura tres 'máquinas': la de la guerra, la de la visión (o del espectáculo) y la de la carne (37). Esta última corresponde a la "[...] red de instituciones especializadas en genética, biología celular, bioquímica, reproducción humana, neurología y farmacología, combinadas con una tecnocracia de la visión interior y la cirugía" (37). Las fantasías de corte neuropunk muchas veces revelan que nuestros cerebros son otro engranaje de nuestra hiperracionalización. De hecho, nuestra materia gris configura en sí misma una cuarta máquina, que libera a medida

${ }^{31}$ En 1987, el escritor K. W. Jeter acuña el término de steampunk para referirse a relatos del tipo "pasado alternativo", ubicados en la época victoriana, que describen tecnologías asombrosas basadas en la máquina de vapor. Este subgénero es una manifestación artística asociada al "retrofuturismo". La segunda se muestra abigarrada de información; presenta, entre una larga lista de personajes, versiones cyberpunk de Isaac Newton y Gottfried Leibnitz, quienes se enfrentan para descifrar el misterio de su universo virtual, que está dentro de otros, y fue creado por un grupo de programadores llamado los Alquimistas de la Matriz. En esta obra, son abarcados rudimentos de alquimia, cábala, cyberpunk y la teoría de cuerdas.

32 Se lee también que "a este millonario colombiano le faltaban varias tuercas y tornillos en el cerebro y que Borges para él era una obsesión" (5; énfasis mío). 
que oprime. A la postre, esta mitología científico-literaria en torno al cerebro es esclava de su fragor liberador.

\section{BiBLIOGRAFÍA}

Abraham, Carlos. Borges y la ciencia ficción:particularidades de la asimilación de un género de la literatura de masas por la literatura canónica. Buenos Aires: Editorial Quadrata, 2005.

Adler, Hans y Sabien Gross. "Adjusting the Frame: Comments on Cognitivism and Literature.” Poetics Today 23/2 (2002): 195-220.

Alonso, Carlos J. The Burden of Modernity. Nueva York: Oxford UP, 1998.

Arango, Ángel. “A dónde van los cefalomos?” ¿A dónde van los cefalomos? La Habana: Cuadernos R, 1964: 13-26.

Síder. La Habana: Unión de Escritores y Artistas de Cuba, 1994.

Areco, Macarena. "Más allá del sujeto fragmentado: las desventuras de la identidad en Ygdrasil'. Revista Iberoamericana LXXVI/232-233 (2010): 839-853.

Ballard, James. “Which Way to Inner Space?” New Worlds 118 (1962): 117.

Baradit, Jorge. Ygdrasil. Santiago: Ediciones B, 2005.

Barthes, Roland. (1957). "El cerebro de Einstein". Mitologias. Tr. Héctor Schmucler. México DF: Siglo XXI editores, 1980: 55-7.

Bioy Casares, Adolfo. Dormir al sol. Madrid: Alianza Editorial, 1979.

La invención de Morel. D. Martino, ed. Caracas: Biblioteca Ayacucho, 2002.

Burgos López, Campo Ricardo. El clon de Borges. Granada: Grupo Editorial AJEC, 2011.

Cabiya, Pedro. La cabeza. San Juan: Isla Negra, 2005.

Malas hierbas. Barcelona: Zemi Book, 2010.

Cano, Luis. "Cárcel de árboles de Rodrigo Rey Rosa y la Meta-Ciencia-Ficción”. Revista Iberoamericana LXXVIII/238-239 (2012): 389-403.

Intermitente recurrencia: ciencia ficción y el canon literario hispanoamericano. Buenos Aires: Corregidor, 2006.

Castera, Pedro. Querens. México, DF: UNAM, 1987. 387-458.

Chalmers, David J. "The Matrix as Metaphysics." Science Fiction and Philosophy: From Time Travel To Superintelligence. Susan Schneider, ed. Chichester: WileyBlackwell, 2009. 33-152.

Chaviano, Daína. Fábulas de una abuela extraterrestre. La Habana: Letras Cubanas, 1998.

“Amoroso planeta". Amoroso planeta. La Habana: Letras Cubanas, 1983. 154180.

Cohen, Marcelo. “El nacimiento del posthumano". El porteño 1/3 (2000): 36-38. 
Correa, Hugo. Los altísimos. Valparaíso: Ediciones Universitarias de Valparaíso, 1983. Los titeres. Santiago de Chile: Zig-Zag, 1969.

Daly, Nicholas. Literature, Technology, and Modernity, 1860-2000. Cambridge: Cambridge UP, 2004.

Del Río, Marcela. Proceso a Faubritten. México, DF: Aguilar, 1976.

Domecq, Bustos. "Los inmortales". Obras completas en colaboración. Jorge Luis Borges. Buenos Aires: Emecé Editores, 1991. 365-368.

Dornbierer, Manú. “La grieta”. La grieta y otros cuentos. México, DF: Diana, 1978.

Enríquez, Orlando. Cuando llegaron los dioses. Tegucigalpa: Secretaría de Cultura, 2001.

Fernández, Bernardo. El estruendo del silencio. México, DF: Suma de Letras, 2009. 133-288.

Gel azul. México, DF: Suma de Letras, 2009. 11-130.

Fernández Delgado, Miguel Ángel. "Pablo Castera". Latin American Science Fiction Writers: An A-to-Z Guide. Darrel Lockhart, ed. Westport, CT: Greenwood Press, 2004. 50-51.

Flanagan, Owen. "Mind, History of the Philosophy of". The Oxford Companion to Philosophy. <http:// www.oxfordreference.com.myaccess.library.utoronto.ca/ views/ ENTRY.html?subview=Main\&entry=t116.e1609>. 20 ago. 2011.

Galán, Jorge. El sueño de Mariana. Guatemala: F\&G Editores, 2008.

Gandolfo, Elvio E. El libro de los géneros. Buenos Aires: Norma, 2007.

Gardini, Carlos. "Primera línea". Qubit 25 (2007): 33-40.

Gil Pérez, Gabriel J. "Incidente Johnson-Muñoz”. En sus marcas, listos... ifuturo! Cuentos cubanos de ciencia ficción deportiva. La Habana: Gente Nueva, 2011. $<$ http:// axxon.com.ar/rev/192/c-192cuento4.htm>.

González, Nelson Darío. De mentes, entes y dementes: Un repaso histórico-crítico de la ciencia ficción hispanoamericana. Desde sus orígenes hasta nuestro días (1870-2013). Tesis doctoral. U of Toronto, 2014.

Haney, Willam S. Cyberculture, Cyborgs and Science Fiction. Consciousness and the Posthuman. Amsterdam: Rodopi, 2006.

Holmberg, Eduardo. "Horacio Kalibang o los autómatas". Historias futuras: antología de la ciencia ficción argentina. Adriana Fernández y Edgardo Pígoli, eds. Buenos Aires: Emecé Editores, 2000. 5-37.

Jeeves, Malcolm. "The Emergence of Human Distinctiveness: The Story from Neuropsychology and Evolutionary Psychology." Rethinking Human Nature: A Multidisciplinary Approach. Grand Rapids, MI: Eerdmans, 2011. 176-204.

Lavín, Guillermo. "El futuro es tiempo perdido". Más allá de lo imaginado. Antología de ciencia ficción mexicana. Vol. 1. México DF: Consejo Nacional para la Cultura y las Artes, Fondo Editorial Tierra Adentro, 1991. 
Londoño, Julio César. "Pesadilla en el hipotálamo". Los geógrafos. Bogotá: Seix Barral, 1999. letralia.com. 6 sept. 1999. <http://www.letralia.com/77 /le05-077. $\mathrm{htm}>.7$ oct. 2013

Lugones, Leopoldo. "Un fenómeno inexplicable". Las fuerzas extrañas. Madrid: Cátedra, 1996. 125-35.

Meier, Sergio. La segunda enciclopedia de Tlön. Santiago de Chile: Puerta de escape, 2007.

Mond, F. Cecilia después o ¿por qué la Tierra? La Habana: Gente Nueva, 2008.

Nervo, Amado. El donador de almas. México, DF: Libro-Mex. Editores, 1955.

Nicolson, Malcolm. "Death and Birth." The Cultural History of the Human Body. Linda Kalof y William Bynum, eds. London: Berg Publishers, 2010. 23-41.

Oesterheld, Héctor Germán, y Francisco Solano López. El Eternauta: 1957-2007, 50 años. Buenos Aires: Doedytores, 2007.

"Inocente Maquiavelo Reforzado". Nueva Dimensión 33 (1972): 42-60.

Palacio, Pablo. "La doble y única mujer". Obras completas. Guayaquil: Casa de la Cultura Ecuatoriana, 1976. 46-54.

Pestarini, Luis. "El boom de la ciencia-ficción argentina en la década del ochenta". Revista Iberoamericana LXXVIII/238-239 (2012): 425-439.

Ramírez, José Luis. "Cyberpunk: El movimiento en México". Ciencia ficción mexicana. 2005. <http://cfm.mx/?cve=11:09>. 10 enero 2013.

Rojas, Ricardo. "La psiquina". Doce cuentos para leer en el tranvía: Una antología de La novela semanal. Margarita Pierini, ed. Bernal: Universidad Nacional de Quilmes, 2009. 179-200.

Rojo, Pepe. "Conversaciones con Yoni Rei". Yonke. México, DF: Times Editores, 1998. 69-83.

Punto cero. México, DF: Times Editores, 2000.

Ruido gris. México, DF: Universidad Autónoma Metropolitana, 1996.

Roncagliolo, Santiago. Tan cerca de la vida. Madrid: Alfaguara, 2010.

Schlich, Thomas. "The Technological Fix and the Modern Body: Surgery as a Paradigmatic Case." The Cultural History of the Human Body. Linda Kalof y William Bynum, eds. Londres: Berg Publishers, 2010: 71-92.

Schneider, Luis Mario. Introducción. "Pedro Castera: un delirante del siglo XIX". Las minas y los mineros. Querens. México, DF: UNAM, 1987. 5-28.

Slusser, George. "Dimorphs and Doubles: J.D. Bernal's 'Two Cultures' and the Transhuman Promise." Science Fiction and the Two Cultures: Essays on Bridging the Gap between the Sciences and the Humanities. Gary Westfahl y George Slusser, eds. Jefferson, NC: McFarland \& Company, 2009. 96-129.

Solomonoff, Pablo. "Eduardo Holmberg: Eslabón perdido en Marte". Viaje maravilloso del señor Nic-Nac. Buenos Aires: Ediciones Colihue, 2006. 11-24. 
Suvin, Darko. Metamorphoses of Science Fiction: On the Poetics and History of a Literary Genre. Londres: Yale UP, 1979.

Tallis, Raymond. Aping Mankind: Neuromania, Darwinitis and the Misrepresentation of Humanity. Durham, UK: Acumen, 2011.

Tandon, A. P. “The Decade of the Brain: A Review.” Neurology India 48 (2000): 199207.

Tapia y Rivera, Alejandro. Póstumo el envirginado. Historia de un hombre que se coló en el cuerpo de una mujer. San Juan: Imp. José González. 1882.

Póstumo el transmigrado. El hombre que resucitó en el cuerpo de su enemigo. Madrid: Imp. Fundición y esterotipia de D. Juan Aguado, 1872.

Vidal, Fernando. "Human Persons and Human Brains: A Historical Perspective within the Christian Tradition." Rethinking Human Nature: A Multidisciplinary Approach. Malcolm Jeeves, ed. Grand Rapids, MI: William B. Eerdmans Pub. Co., 2011. 30-59.

Urzaiz, Eduardo. Eugenia: Esbozo novelesco de costumbres futuras. Mérida, Yucatán: Zamná, 1947. 